\title{
Ergonomics in Design, current development and new challenges
}

\author{
Francesca Tosi \\ University of Florence, Department of Architecture, Laboratory of Ergonomics in Design, \\ Via Sandro Pertini 93, 50041 Calenzano, Florence, Italy \\ E-mail: francesca.tosi@unifi.it.
}

Received 22 May 2019

Accepted 1 July 2019

\section{Introduction}

There are many fields of application for Ergonomics, and many specialisations for individual researchers and/or professionals. The contents, methods and research results offered by the scientific literature of the sector, and presented at the international Ergonomics conferences, offer a vast panorama: from workplace safety to Human-Computer Interaction, from clinical risk management to User Experience, from the study of organisations to the design of products for use. The picture that emerges is one of a very vast puzzle of research areas, professional skills and specialisations - each characterised by its own scientific references - investigation and intervention methods, often from its own languages, whose contents wholly belong to both specific disciplinary areas and/or professional environments in which each ergonomic researcher or professional works, and the various specialisations of Ergonomics (see Fig. 1).

The IEA identifies three specialist areas - Physical ergonomics, Cognitive ergonomics, Organisational ergonomics - which are articulated and in close collaboration with the various application and intervention sectors.

As S. Shorrock and C. Williams [1] write: "Human Factors and Ergonomics (HF/E), as a professional activity, has now been introduced to almost all economic sectors. In the primary sector, HF/E helps to improve human involvement in mining, oil and gas extraction, agriculture, and forestry. In secondary sector, $\mathrm{HF} / \mathrm{E}$ is embedded in manufacturing and construction to produce finished products. In tertiary (service) sector, hospitals and health-care organization, telecommunications, wholesale and distribution organizations, and governments all employ or contract $\mathrm{HF} / \mathrm{E}$ services. In the quaternary (knowledge based) sector, HF/E practitioners are employed in information and technology, media, education, research and development (R\&D), and consultancy organizations".

In all these sectors the ergonomic intervention takes shape today - also - as a design intervention, in which Design plays an essential role in system innovation.

The development of an area of ergonomics specifically aimed at the design - as well as the integration of the ergonomics skills and intervention tools within the design processes - and in particular within industrial design and development processes - represent a still recent phenomenon, which originates in many factors that have progressively approached both the objectives and the fields of interest and intervention of ergonomics and design.

The first factor is the progressive extension of the research and intervention fields of ergonomics, which has brought its areas of interest to all human activities (work, daily life, use of services) and, in parallel, to its openness to the study and design of the most strictly subjective components of 


\section{Physical Ergonomics}

is concerned with human anatomical, anthropometric, physiological and biomechanical characteristics as they relate to physical activity. (Relevant topics include working postures, materials handling, repetitive movements, work related musculoskeletal disorders, workplace layout, safety and health).

\section{Cognitive ergonomics}

is concerned with mental processes, such as perception, memory, reasoning, and motor response, as they affect interactions among humans and other elements of a system. (Relevant topics include mental workload, decision-making, skilled performance, human-computer interaction, human reliability, work stress and training as these may relate to human-system design.)

\section{Organizational ergonomics}

is concerned with the optimization of sociotechnical systems, including their organizational structures, policies, and processes. (Relevant topics include communication, crew resource management, work design, design of working times, teamwork, participatory design, community ergonomics, cooperative work, new work paradigms, virtual organizations, telework, and quality management.)

Fig. 1. Areas of ergonomic specialisation. Source: IE, International Ergonomics Association, www.iea.cc, 2019.

\section{Chief sectors of Ergonomic intervention:}

- Health and safety of work stations and environments

- Musculoskeletal disorders

- Human error and reliability of systems

- Work organisation and psycho-social factors

- Usability

- User experience

- Systems design ( $\mathrm{HMI}, \mathrm{HCl})$

- Human performance

- Management of clinical risk

- Design for all

- Product design and interior design

- Communicative design

- ..............................

Fig. 2. Ergonomic intervention sectors. Source: SIE, Società Italiana di Ergonomia e fattori umani, www.societadiergonomia.it.

human-environment-product interaction, connoting ergonomics as a "global approach" to the evaluation and design of the relationship between the individual and the artefacts that make up its material environment.

The second factor, the increasing technological complexity of industrial products and, in particular of everyday products, which imposes an equally increasing attention of companies towards the devel- opment of design solutions capable of making the interfaces of dialogue between user and product accessible and comprehensible, in parallel, the ever greater complexity of the design and production processes, characterized by the compression of the time required for the development and verification of the project idea, and by the need to control from the early stages of the project every technical, productive and economic aspect of its realization. 
The third factor can be identified in the attention paid to the actual level of quality offered by the products, which has been spreading over the past few years in ever wider segments of potential users/consumers, parallel to the awareness of their own needs and expectations regarding performance, reliability, the aesthetic and emotional value of the product, and the ability to choose between the now immense number of alternatives offered by the market.

From these factors of change derives the growing interest with which designers and companies are now turning to survey and evaluation tools capable of orienting their design and production choices towards solutions able to reach the new needs expressed by the market and to guarantee a quality of the product capable of translating into the actual satisfaction of potential users/buyers.

And it is precisely the quality of the product understood as correspondence to the real needs and desires of users/consumers, and as the ability to guarantee maximum safety, reliability and pleasant use in the different and possible conditions of its use - to represent the sector of privileged research of some of the most advanced areas of ergonomics and, at the same time, the "common ground" on which ergonomic research and experimentation meet today with the objectives of design research and production strategies aimed at achieving the specificity of needs of potential users/consumers.

\section{The role of Design}

Design, and its design methods, are now recognised on a global level as strategic factors for innovation and social and economic growth.

In the European Union documents regarding strategies for innovation, Design is defined as "a key discipline and activity to bring ideas to the market, transforming them into user-friendly and appealing products or services (...) Design provides a series of methodologies, tools and techniques that can be used at different stages of the innovation process to boost the value of new products and services. When applied to services, systems and organisations, user-centred design thinking drives business model innovation, organisational innovation and other forms of non-technological innovation. These methodologies may also be instrumental when addressing com-plex and systemic challenges, for example in redesigning public services and in strategic decision-making processes" [2].
The role of Design is defined chiefly as designintervention activities based on the capacity for innovation and, moreover, the capacity for synthesis and connection between the different professional skills involved in the trai-ning and development processes for new products and services and, more generally, the decision-making processes in production and social areas.

In fact, Design is - by definition - a capacity for creative synthesis, based on the ability to imagine and make innovative design solutions achievable, and develop them into a finished product.

The role of the designer is linked to his design ability, that is, his ability to intervene on what already exists, based on his capacity to interpret the complexity of the innovative and changing factors that surround us and to develop intervention solutions that can respond to people's needs, expectations and desires, while also proposing new behaviours and suggesting new lifestyles.

This innovation can be configured in many ways: from the application of a new material to the original application of traditional materials, from the ability to provide new answers to consolidated needs and expectations to the ability to interpret as-yet unexpressed needs. More generally, the innovations can be configured as "advances in the performance of products that are made possible by frontier technologies and product improvements suggested by a more efficient analysis of client needs. The former is the domain of radical technology-driven innovation (technology push); the latter is the domain of incremental market-based innovation (market pull)" [3].

A second, no less important, aspect to be highlighted is the role of Design as a connective factor between different disciplinary and professional skills and specificities. The professional designer and, more generally, Design as a field of research and intervention, operates within a system of skills that are typically well articulated, in which each intervention is tackled using operational tools and perspectives that are very distant.

Both the articulation of the meanings attributed to Design and the intervention methods that the different versions of Design can now offer to the complexity of the processes for training and developing products, goods and services are essential.

"There has been a shift in understanding during the last 10-15 years towards a more strategic view of design in business, and towards design as 
an essential activity for user-centred innovation in business, academia and (although to a lesser extent) in policy making. This has resulted in a number of schools of thought about the contribution of design, and new terminology including labels such as 'strategic design', 'design management', 'concept design' and 'design thinking'. The schools of thought may all have their own particularities, but they also have a number of points in common, namely:

- Focus on user-centred problem solving: Design is seen as a way of identifying and solving user problems by for example studying users and/or by involving them through visualisation and participatory design techniques such as co-creation. User-centred design innovation stresses human needs, aspirations and abilities, and strives for holistic and visionary solutions.

- Design as a multidisciplinary and crossfunctional innovation activity: The designer facilitates cross-disciplinary innovation processes and interactions by bringing together individuals from different corporate functions within a company, such as management, engineering and marketing, but may also bring in expertise from disciplines such as psychology, sociology, anthropology and arts.

- Design as a holistic and strategic activity: Design considerations - i.e. putting the user at the centre - permeate the innovation process, from product development, customer service and management up to the highest levels of hierarchy. Rather than 'design as styling' added on towards the end of the product development process, the user is the focus in earlier (more strategic) phases. Design is a core element of company strategy and helps visualise possible scenarios to support strategic decision making" [2].

Thus, Design is described and required as a tool for innovation, both as it relates to the capacity for design intervention - that is, the ability to provide a design response to complex requests and requests coming from the company and the production system, from the social system and the reference user (which are not always the same and cannot always be reconciled with each other) - and as it relates to the intervention methods which Design can act within and use to interact with this system.

Even when designing products that are not very complex, such as furnishings or individual everyday products, Design operators within design and production processes that involve production technicians, IT engineers, marketing managers, etc. and, naturally, acts within and/or in close collaboration with the corporate structure and its organisational features.

The complexity of the production system requires the ability to synthesise different problems and requests and, when necessary, to be able to communicate and compare very different skills, languages and work and intervention tools.

The designer is required to find the most suitable solution based on the instructions and the limitations which concern the availability and processing methods for materials, product times and costs, organisation - and geographic location - of the production line(s), the market expectations as identified by marketing and, of course, the procurement methods, the supplier network for materials and semifinished goods, the distribution network for products, etc.

Today the new challenges of ergonomics and design are important. The development of a designplanning approach, centered on technological and formal innovation and capable of proposing new solutions.

An upcoming WORK special issue will also be dedicated to this theme, which will still present new experiences and experimentations of Ergonomics and Design.

\section{References}

[1] Shorrock S, Williams C. Human Factors and Ergonomics in Practice: Improving System Performance and Human WellBeing in the Real World. Boca Raton: CRC press; 2017. pp. 3.

[2] European Commission. Design as a driver of user-centred innovation. In: EU Commission staff working document. Brussels. 2011.

[3] Verganti R. Design driven innovation. Milano: Etas; 2009. pp. 4. 